\title{
Clinical Features, Management, and Outcomes of Chest Trauma at a Tertiary-Care Centre in India: A Retrospective Observational Study
}

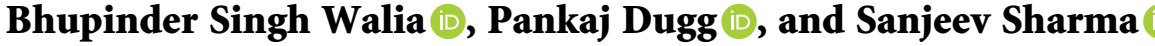 \\ Department of General Surgery, Government Medical College, Amritsar, Punjab, India \\ Correspondence should be addressed to Pankaj Dugg; dr_dugg@hotmail.com
}

Received 14 August 2021; Revised 26 October 2021; Accepted 5 November 2021; Published 16 November 2021

Academic Editor: Ahmad Mansour

Copyright ( $\odot 2021$ Bhupinder Singh Walia et al. This is an open access article distributed under the Creative Commons Attribution License, which permits unrestricted use, distribution, and reproduction in any medium, provided the original work is properly cited.

\begin{abstract}
Introduction. Chest is one of the main sites of injuries in trauma being a part of the torso. Many important organs lie in rib cage. However, data on chest injuries are scarce. Methods. A retrospective study was carried out for chest trauma patients including polytrauma $(n=184)$ from hospital records for five years $(2016-2020)$. Various parameters including demographic profile, mode of injury, management, and outcomes were studied. Results. Mean age of patients was $37 \pm 16$ years with a male to female ratio of $2.4: 1$. Road traffic injuries remained the most common cause of trauma followed by assaults. Most of the patients were managed conservatively (55.43\%). Mortality was seen in only $1.63 \%$ patients. Conclusion. Young male patients are usually affected by trauma. Road traffic injuries are the commonest cause. However, most patients can be managed by conservative treatment and mortality is seen only in polytrauma patients in the present study.
\end{abstract}

\section{Introduction}

Traumatic injuries lead to 5.8 million deaths each year which accounts for $10 \%$ of the world's deaths. A trauma-related death is reported every 1.9 minutes in India [1]. Nearly 20 million are hospitalized every year due to injuries out which 1 million die due to trauma-related injuries [2].

Chest trauma accounts for about $10 \%$ of all trauma admissions and $25-50 \%$ of trauma deaths globally. The severity of chest trauma and associated comorbidities has been seen to determine the mortality due to chest trauma [3]. It has been reported that chest trauma is directly related to mortality in $25 \%$ of cases and has been a contributing factor in another $25 \%$; however, a majority of patients ( $80 \%)$ can be managed with intercoastal chest tube drainage and appropriate analgesia and respiratory support [4].

The incidence of chest injuries has increased due to highspeed vehicular travels. It leads to life-threatening conditions such as tension pneumothorax, massive hemothorax, and injury to larger vessels [5]. The variation in the etiological pattern of chest trauma worldwide is attributed to many environmental and sociopolitical factors, but road traffic accidents (RTAs) remain the commonest cause of chest trauma in nonwar zones of the world [6].

Chest injuries have been associated with significant mortality. Although there is increased frequency of chest trauma patients in hospitals, data regarding the chest trauma are scarce [7].

A retrospective study is conducted on all chest trauma patients presented to our hospital between January 2016 and December 2020 to look for the management and outcome.

\section{Methods}

The study was carried out in a tertiary-care center. All patients admitted to department of surgery with chest trauma (including multiple trauma or exclusive chest injuries) were included in the study $(n=184)$. This study was based on retrospective observational analysis of data from hospital records from Jan 2016 to Dec 2020. 
TABle 1: Demographic profile $(n=184)$.

\begin{tabular}{lccc}
\hline Age in years & Male & Female & Total \\
\hline$<10$ & 2 & 2 & $4(2.17 \%)$ \\
$11-20$ & 10 & 12 & $22(11.96 \%)$ \\
$21-30$ & 46 & 10 & $56(30.43 \%)$ \\
$31-40$ & 22 & 2 & $24(13.04 \%)$ \\
$41-50$ & 30 & 14 & $44(23.91 \%)$ \\
$51-60$ & 12 & 10 & $22(11.96 \%)$ \\
$>60$ & 8 & 4 & $12(6.52 \%)$ \\
Total & 130 & 54 & 184 \\
Mean \pm SD (years) & $36 \pm 15$ & $38 \pm 18$ & $37 \pm 16$ \\
\hline
\end{tabular}

TABLE 2: Mode of injury.

\begin{tabular}{lccc}
\hline Mode of injury & Male & Female & Total \\
\hline Road traffic injury & 72 & 26 & $108(58.69 \%)$ \\
Assaults & 54 & 24 & $78(42.39 \%)$ \\
Falls & 2 & 4 & $6(3.26 \%)$ \\
Railway accidents & 2 & 0 & $2(1.09 \%)$ \\
\hline
\end{tabular}

TABLE 3: Type of chest injury.

\begin{tabular}{lc}
\hline Type of injury & No. of cases \\
\hline Bruise & 30 \\
Abrasion & 76 \\
Laceration & 14 \\
Fractured ribs & 30 \\
Fractured clavicle & 20 \\
Flail chest & 8 \\
Pulmonary contusions & 10 \\
Pneumothorax & 16 \\
Hemothorax & 30 \\
\hline
\end{tabular}

The analyzed data included demographic profile, mode of injury, types of chest injuries, management, and outcome.

Statistical analysis was conducted on SPSS software windows version 20. The ANOVA test was used for univariate analysis. The chi square test was used for comparison. A $P$ value of $<0.05$ was considered significant. Microsoft excel worksheet version 2016 was used to calculate mean and standard deviation. Nominal data were presented as percentage.

\section{Results}

A total of 184 patients' data were included in the study who were admitted in the hospital with chest injury in last 5 years (Jan 2016 to Dec 2020).

Out of 184 patients, a majority of patients belonged to the age group of $21-30$ years, i.e., $30.43 \%$, followed by the age group of $41-50$ years, i.e., $23.91 \%$. The mean age of males and females was $36 \pm 15$ and $38 \pm 18$ years, respectively. Overall mean age was $37 \pm 16$ years (Table 1 ). The male to female ratio was $2.4: 1$.

Most of the injuries in this study were from road traffic accidents $(n=108,58.69 \%)$. Assaults were the second most common mode of injury $(n=78,42.39 \%)$. Other modes are less common (Table 2). A majority of patients had blunt trauma chest, and only $2 \%$ had penetrating trauma.

Among the type of injuries, abrasions were most common $(n=76)$ followed by bruises, hemothorax, and fracture ribs (Table 3). However, there were multiple findings in some cases. Exclusive chest injuries were seen in less number of patients $(n=57)$. A majority of patients had associated head injuries $(n=110)$. Associated abdominal injuries were seen in 16 patients, while one patient had both abdominal and head injuries (Figure 1).

Most of the cases were managed conservatively $(n=102$, $55.43 \%$ ). Only 68 patients required intercoastal chest tube drainage (36.96\%) (Table 4). However, findings were not statistically significant as $P$ value $>.05$.

Mortality is seen in $1.63 \%$ patients, while $79.35 \%$ $(n=146)$ were discharged in a satisfactory condition (Table 5). The three patients who expired had other injuries also. Two patients were of road traffic injuries having head injury with multiple rib fractures, while one patient was of railway track injury having head injury, abdominal injury (liver laceration), and flail chest.

Five patients were referred due to associated head injuries as the neurosurgeon was not available at our institute.

\section{Discussion}

Chest trauma contributes $10-15 \%$ of all trauma cases and is the root of $25-30 \%$ of all deaths due to trauma, making it an important health condition [8]. Most of the times, chest trauma is managed by general surgeons and thoracic surgeons are rarely a part of the team managing chest trauma [9]. Our institute is the referral centre of the region covering around five districts. Although there is no specific thoracic trauma unit, all the trauma cases are managed by general surgeons.

The mean age of patients affected by chest trauma were $37 \pm 16$ years, thus showing it affects younger age groups more commonly. The most common age group affected was 21-30 years (30.43\%) followed by $41-50$ years $(23.91 \%)$. Kant et al. reported an average age of 36.25 years in patients of chest trauma [1]. Ibrahim et al. reported the maximum number of cases in the age group of 20-30 years with a decrease in the number of cases with an increase in age [8]. A similar trend is seen in our study after the age group of 41-50 years. Male population is most commonly affected in our study with a male to female ratio of $2.4: 1$. It was consistent with the study conducted by Liman et al. where males (70.6\%) were predominantly affected as compared to female (29.4\%) patients [10]. Male to female ratio in studies conducted by Kant et al. and Ekpe et al. was $3.54: 1$ and $4: 1$, respectively $[1,3]$. The reason for increased male population involved in trauma may be due to the reason that, in our country, most of the outdoor activities are carried out by male population but trends are changing in coming times and the findings in future may be different. Moreover, younger age groups have aggressive behavior and they are involved in dangerous driving and quarrels.

Road traffic injuries were the most common mode of injury $(58.69 \%)$ in present study followed by assaults 


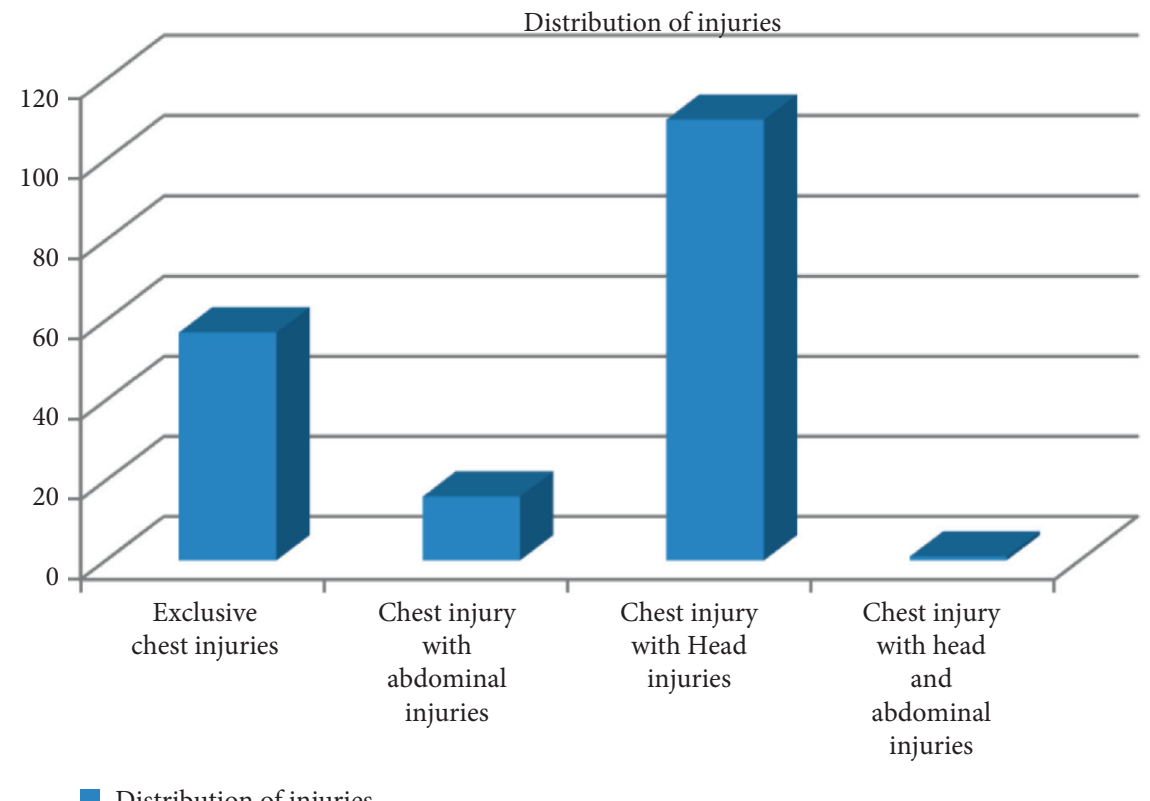

Distribution of injuries

FIgURE 1: Distribution of injuries.

TABLE 4: Management profile of patients.

\begin{tabular}{lc}
\hline Management/outcome & No. of cases \\
\hline Suturing under LA & $14(7.61 \%)$ \\
Conservative & $102(55.43 \%)$ \\
Intercoastal chest tube drainage & $68(36.96 \%)$ \\
$P$ value & 0.686576 \\
\hline
\end{tabular}

TABLe 5: Outcome of chest injury patients $(n=184)$.

\begin{tabular}{lc}
\hline Outcome & No. of cases \\
\hline Discharged & $146(79.35 \%)$ \\
Referred & $5(2.72 \%)$ \\
Left against medical advise & $30(16.67 \%)$ \\
Expired & $3(1.63 \%)$ \\
\hline
\end{tabular}

$(42.39 \%)$. Although statistically findings are not significant $(P<0.05)$, assaults have become an important health problem in the society. As per the National Health Portal, road traffic injuries lead to five million deaths annually around the world. In India, one million die each year and around 20 million are hospitalized due to injuries. In 2015, the National Crime Records Bureau (NCRB) reported 413,457 deaths in road traffic injuries [11]. Kant et al. and Anisuzzaman et al. had similar findings with respect to mode of injury like the present study with road traffic injuries $(63 \%)$ as the most common cause followed by assaults $[1,6]$. Liman et al. and Mathangasinghe et al. reported road traffic injuries $(67.79 \%)$ as the most common cause of chest trauma followed by falls $[10,12]$. However, Ibrahim et al. reported assaults (42\%) as the most common cause of chest trauma. The reason cited by them was characters of population activities in the area surrounding hospital [8]. Mode of trauma is blunt in majority cases with a ratio of $49: 1$ between blunt injuries and penetrating injuries in our study.
Anisuzzaman et al. found only $0.8 \%$ cases of penetrating trauma in his study which is in accordance with the present study [6].

The most common injury reported in our study was abrasion $(n=76)$. Serious injuries such as hemothorax $(n=30)$, pneumothorax $(n=16)$, and flail chest $(n=8)$ associated with it were comparatively less. Choudhary et al. concluded in his study that most patients had soft-tissue injury and only intervention required in the study was intercoastal drainage [13]. In studies conducted by Kant et al. and Liman et al., the most common injury in the chest was rib fractures and flail chest $[1,10]$. Ibrahim et al. reported open chest wall injuries as the most common presentation of chest injuries. The reason could be assaults contributing to the most common mode of injury [8]. Adegboye et al. in his study reported that blunt chest injuries lead to minor chest wall injuries (68\%), major but stable chest wall injuries (7.6\%), and flail chest injuries (10.8\%). Thoracic injuries without fractures of bony chest wall occurred in $13.6 \%$ patients [14].

A majority of patients had associated head injuries in the present study with exclusive chest injuries seen in 30.97\% patients only. Anisuzzaman et al. reported the most common associated injury was of the extremity followed by abdominal injury [6]. Mathangasinghe et al. also reported extremity injury as most common associated injury followed by head injury [12]. However, Choudhary et al. reported soft-tissue injuries in the form of lacerations as the common extrathoracic injuries [13].

Most of the patients were managed conservatively (55.43\%), and only $68(39.69 \%)$ patients required chest tube drainage. Most of the times, patients of chest trauma required conservative management only. No patient in the present study required thoracotomy. Kant et al. reported similar findings with $82 \%$ patients managed conservatively 
and $15 \%$ required chest tube drainage [1]. Kulshrestha et al. in their study concluded that most of chest trauma patients can be managed conservatively. In their study, only $18.32 \%$ patients required chest tube drainage and $2.6 \%$ required thoracotomy [7]. Liman reported that $25.7 \%$ patients required needle decompression out of which 2 patients required mediastinotomy. All patients of flail chest were managed in the intensive-care unit [10]. However, in study of Ibrahim et al., 58\% patients required surgical interventions [8]. This could be due high number of open chest wall injuries.

In present study, a majority of patients (79.35\%) were discharged in a satisfactory condition. Five patients required referral to a higher centre due to associated head injury. Mortality rate was $1.63 \%$. Patients who expired had multiple injuries including abdominal and head injuries. All three patients belonged to higher age groups (>65 years). Mortality reported by Kulshreshtha et al. and Ibrahim et al. was $9.41 \%$ and $18 \%$, respectively $[7,8]$. Mortality rate reported by Kant et al. is 2\% [1]. Ekpe et al. reported that mortality in chest trauma is determined by associated extrathoracic organ injury, late presentation beyond 24 hour posttrauma, and severe chest injury with bilateral chest involvement [3].

Road traffic accidents are one of the increasing health problems in India and are becoming epidemic. Younger age groups are more commonly injured in traffic accidents. The causes are driving under the influence of alcohol and overspeeding [15]. Evidence-based interventions are required to improve road safety, enhance the involvement of the health system to deal with road injuries, and improve availability of quality actionable data. An improved plan for targeted interventions is required to achieve the Sustainable Development Goal (SDG) target by 2030 [16].

\section{Conclusions}

Road traffic injuries are the most common cause of chest trauma. However, assaults are also significantly increasing as an important cause of chest trauma. Mainly the young male population is being affected. Most of the times, chest trauma is managed conservatively and it has low mortality. Significant steps are required to prevent road traffic injuries and counselling sessions for younger adults involved in assaults.

\section{Data Availability}

Data can be obtained from the corresponding author, e mail: dr_dugg@hotmail.com.

\section{Conflicts of Interest}

The authors declare no conflicts of interest regarding the publication of this paper.

\section{References}

[1] K. C. Kant, K. S. Kant, and M. Noman, "A study to evaluate the clinico-etiologic profile and management of patients with trauma to the chest in a tertiary care Hospital," European Journal of Molecular and Clinical Medicine, vol. 7, no. 8, 2020.
[2] J. V. Sakran, S. E. Greer, E. Werlin, and M. McCunn, "Care of the injured worldwide: trauma still the neglected disease of modern society," Scandinavian Journal of Trauma, Resuscitation and Emergency Medicine, vol. 20, no. 1, p. 64, 2012.

[3] E. E. Ekpe and C. Eyo, "Determinants of mortality in chest trauma patients," Nigerian Journal of Surgery : Official Publication of the Nigerian Surgical Research Society, vol. 20, no. 1, pp. 30-4, 2014.

[4] J. O'Connor and J. Adamski, "The diagnosis and treatment of non-cardiac thoracic trauma," Journal of the Royal Army Medical Corps, vol. 156, no. 1, pp. 5-14, 2010.

[5] U. Farooq, W. Raza, N. Zia, M. Hanif, and M. M. Khan, "Classification and management of chest trauma," Journal of the College of Physicians and Surgeons-Pakistan :JCPSP, vol. 16, no. 2, pp. 101-103, 2006.

[6] M. Md Anisuzzaman, S. N. Hosain, M. M. Reza, M. G. Kibria, and S. Ferdous, "Management of chest trauma in Bangladesh perspective: experience of a decade," Cardiovascular Journal, vol. 12, no. 1, pp. 3-8, 2019.

[7] P. Kulshrestha, I. Munshi, and R. Wait, "Profile of chest trauma in a level I trauma center," The Journal of Trauma, Injury, Infection, and Critical Care, vol. 57, no. 3, pp. 576-581, 2004.

[8] S. R. Ibrahim and A. E. Abdelaziz, "Retrospective statistical study of thoracic trauma patients in Al-hussein hospital, Alazhar university," The Egyptian Journal of Hospital Medicine, vol. 84, no. 1, pp. 1650-1654, 2021.

[9] C. Ludwig and A. Koryllos, "Management of chest trauma," Journal of Thoracic Disease, vol. 9, no. 3, pp. S172-S177, 2017.

[10] S. Liman, A. Kuzucu, A. I. Tastepe, G. N. Ulasan, and S. Topcu, "Chest injury due to blunt trauma," European Journal of Cardio-Thoracic Surgery, vol. 23, no. 3, pp. 374-378, 2003.

[11] National Health portal, World Trauma Day 2019 (Internet), MoHFW, Government of India, 2019, https://www.nhp.gov. in/world-trauma-day-2019_pg [updated 2019 Oct 21].

[12] Y. Mathangasinghe, I. H. D. S. Pradeep, and D. Rasnayake, "Demographic, clinical features and outcome determinants of thoracic trauma in Sri Lanka: a multicentre prospective cohort study," Canadian Respiratory Journal, vol. 2020, Article ID 1219439, 2020.

[13] A. Choudhary, K. Prassad, and P. N. Sreeramulu, "A clinico-epidemiological study of traumatic chest injuries in a rural tertiary care centre in India: our experience," International Journal of Biomedical and Advance Research, vol. 6, no. 2, pp. 110-114, 2015.

[14] V. O. Adegboye, J. K. Ladipo, I. A. Brimmo, and A. O. Adebo, "Blunt chest trauma," African Journal of Medicine and Medical Sciences, vol. 31, no. 4, pp. 315-320, 2002.

[15] M. Kashid, S. K. Rai, S. K. Nath, T. P. Gupta, O. Shaki, and P. Mahender, "Epidemiology and outcome of trauma victims admitted in trauma centers of tertiary care hospitals-a multicentric study in India," International Journal of Critical Illness and Injury Science, vol. 10, pp. 9-15, 2020.

[16] R. Dandona, G. A. Kumar, G. Gururaj et al., "Mortality due to road injuries in the states of India: the global burden of disease study 1990-2017," The Lancet Public Health, vol. 5, no. 2, pp. e86-e98, 2020. 